\title{
Study on Wellhead Growth in Deep Well
}

\author{
Gao Baokui, Ren Jingwei and Gao Liang \\ Department of Petroleum Engineering, China University of Petroleum Beijing, Beijing, 102249, China
}

\begin{abstract}
Wellhead growth has occurred in many deep wells in China recently. In the paper, casing axial force and wellhead movement are calculated and compared in regard to moments that free sections of surface casing appear. The parameters considered include preliminary casing tension, free section length and change in wellbore temperature. The moment that surface casing free section comes into being has great influence on wellhead movement, so it is discussed in detail. According to comprehensive investigation on deep well and ultra-deep well accidents, wellhead growth is based on the fact that before production the cement sheath of surface casing has already failed, and during production wellhead grows up due to wellbore temperature increases. The most possible reason of surface casing cement sheath failure is bad cement job quality. Bad cement sheath cannot support casing axial loads and separates from casing. The free section of surface casing will experience large axial force cycle which is harmful to wellbore integrity. Effective measures to remedy wellhead growth is supporting the wellhead with a large base set on ground, rather than pads fixed on conductor.
\end{abstract}

\section{Introduction}

Wellhead growth is usually occurred in thermal wells and offshore self standing platform wells. In a normal thermal well, only production casing is connected with wellhead and in most cases the well is cemented to surface. When injecting steam or hot water, wellbore is heated, cement sheath may separate from casing and wellhead growth will take place. After injection being stopped the casing will shrink and wellhead will return to its original position, even subside[1, 2]. In an offshore oil well, surface casing has unavoidable free section from mud line to wellhead, therefore some factors, such as casing temperature and annulus pressure, can induce wellhead movement during subsequent constructions. For high level safety, study and achievements are mainly in offshore wells, but calculation methods are generally alike[3-5]. There are little open reports about wellhead growth or subsidence in onshore deep wells, and there is no mechanism study. In fact, accidents of wellhead growth or subsidence in deep wells do exist $[6,7]$. In an abnormal deep well all casing strings are top cemented, so the wellhead growth mechanism is more complex[810]. As an important component of wellbore integrity, wellhead growth in deep well must be solved.

With regard to deep well construction procedure, change in wellhead position and casing axial force is calculated in this paper. Parameters as casing pretension, free casing length and thermal effect are considered. The moment and after effect that surface casing section becomes free are investigated in detail.

\section{Models of wellhead growth}

\subsection{Wellbore structure of deep wells}

A typical wellbore sketch of deep well in China is drawn in Fig. 1.

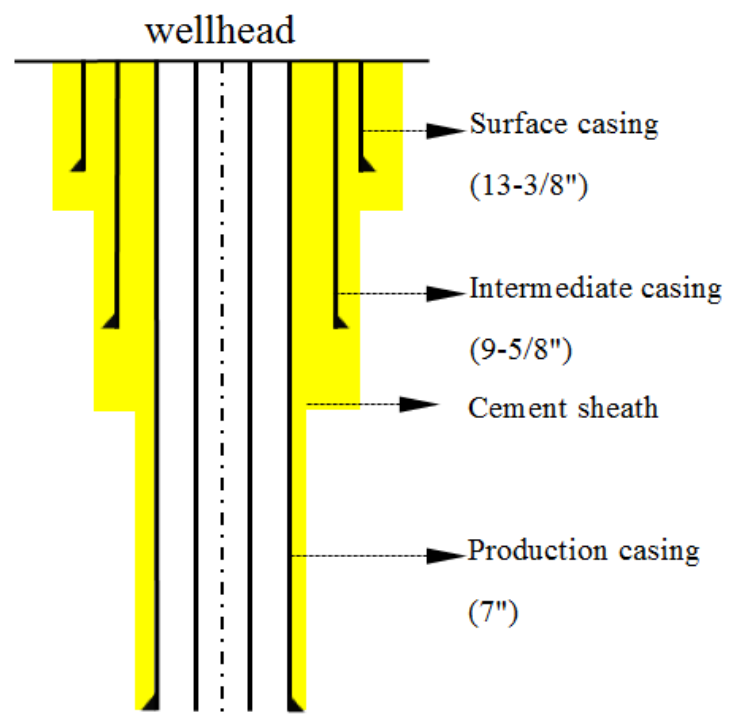

Figure 1. Typical wellbore sketch of deep well.

Generally, wellbore structure has the following characters:

- The first pipe is conductor with depth ranged from $100 \mathrm{~m}$ to $300 \mathrm{~m}$, cemented to surface and will not connect with wellhead. 
- Surface casing is cemented to surface, and it should directly support wellhead loads.

- Based on drilling conditions, intermediate casing and production casing may be top cemented or not top cemented (has free section).

- The liner, if there is, doesn't participate in wellhead growth.

- The main wellbore consists of surface casing, intermediate casing and production casing; these casings joint together at wellhead.

\subsection{Mechanism of wellhead growth}

Treat wellhead as a rigid body, then three layers of casings would grow up simultaneously at top ends. The stiffness of surface casing is much larger than others, so an obvious wellhead growth means that surface casing must have a considerable section that can move axially. Other casings can also have such intervals, and they are termed as free sections throughout this paper. Normally, free section of surface casing comes from bad cement job quality.

The principal work to be done is to find the moment that surface casing free section appears. But wellhead growth is generally observed during production, so the task is very difficult. In order to solve this problem, five moments are proposed as follows:

- Case-1, before hanging intermediate casing,

- Case-2, when hanging intermediate casing,

- Case-3, when hanging production casing,

- Case-4, when hanging tubing,

- Case-5, during production.

It is impossible to give precise conditions of cement sheath failure. So in the following investigation, primary work is performed under the assumption that surface casing free section appears outright while in different moments. Casing axial force and wellhead growth are main parameters to be calculated.

In engineering, it is hard to predict the moment when surface casing free section appears. The most optimistic expectation is to monitor it timely. In view of study and prevention, any possibility should be considered to find out the causality.

Wellhead growth reported now is a height change compared with previous position. If free section forming moment is not identified, it is impossible to trace wellhead movement before the so called growth. In this paper, the reference position of wellhead is the height of surface casing top just after it is cemented. This position doesn't distinguish whether surface casing has free section.

\subsection{Calculation method}

\subsubsection{Initial axial force at top end of casing}

Every casing will be connected to wellhead after cementing. If top of cement reaches to surface and cement job quality is good, there will be solidified pretension in casing wall. It can be regarded as tension of casing to wellhead if this casing appears free section afterward. If casing has scheduled free section, casing will have suspended load when setting at wellhead, and the load is controllable, which is the axial force at top of free casing section.

\subsubsection{Formulas for calculation wellhead growth}

If wellbore temperature changes, free casing section will have thermal effect, and the formula is

$$
d(\delta l)=\alpha \cdot \Delta T \cdot \Delta L
$$

where $\alpha$ is linear expansion coefficient of casing, ${ }^{\circ} \mathrm{C}^{-1} ; \Delta L$ is micro-segment of free casing section, $\mathrm{m} ; \Delta T$ is change in temperature of casing micro-segment, ${ }^{\circ} \mathrm{C} ; d(\delta l)$ is elongation of casing micro-segment due to thermal effect, $\mathrm{m}$.

The temperature difference is different with depth, so integral is needed to obtain total heating effect.

Both temperature effect and wellhead growth of free casing section will associate with the relationship between casing axial force and deformation, which can be written as

$$
d F=(E A / L) \cdot d L
$$

where $E$ is Young's elastic modulus, $\mathrm{kPa} ; A$ is cross sectional area of casing wall, $\mathrm{m}^{2} ; L$ is free casing length, $\mathrm{m}$; $d L$ is axial deformation of free casing section, $\mathrm{m} ; d F$ is change in axial force of free casing section, $\mathrm{kN}$.

Take wellhead as rigid body, the resultant force of wellhead at vertical direction is zero, the equation can be expressed as

$$
F_{1}+F_{2}+\cdots+F_{\mathrm{n}}=0
$$

where $\mathrm{n}$ is the number of forces acting on wellhead; $F_{\mathrm{i}}$ $(\mathrm{i}=1,2, \cdots, \mathrm{n})$ is $i$ th axial force, $\mathrm{kN}$.

More formulas can be found in reference 1 .

\subsubsection{Temperature field}

Temperature increment is the motivator of wellhead growth. So it is necessary to calculate change in temperature in every free casing section. But the calculation is very complicated, which involves wellbore structure, flow rate, fluid components, formation original temperature, flow period, and so on. In the following calculation some results are used directly without analysis in detail.

\subsubsection{Simplification and hypothesis}

In following calculations, some simplifications and hypotheses are used as follows:

- Wellbore is vertical,

- The influence of conductor is neglected,

- The influence of installation and remove of blowout preventer is neglected,

- The length of every free section is given, and its potential extension is neglected. 


\section{Case study}

In this section a deep well in west China is taken as example, casing axial force and wellhead growth are calculated and compared. The length of casing free section is just a possible value in the field, namely is not necessarily the real value because real result is impossible to be identified.

\subsection{Basic parameters}

This deep well is top cemented for every layer of casing, and the wellbore structure is shown in Figure 1, detailed parameters are listed in Table 1.

Table 1. Detailed parameters of wellbore structure.

\begin{tabular}{cccc}
\hline Casing & $\begin{array}{c}\text { Hole } \\
\text { diameter } \\
(\mathrm{mm})\end{array}$ & $\begin{array}{c}\text { Casing outer } \\
\text { diameter } \\
(\mathrm{mm})\end{array}$ & $\begin{array}{c}\text { Casing wall } \\
\text { thickness } \\
(\mathrm{mm})\end{array}$ \\
\hline $13-3 / 8^{\prime \prime}$ & 444.5 & 339.7 & 12.19 \\
$9-5 / 8^{\prime \prime}$ & 311.2 & 244.5 & 11.05 \\
$7 "$ & 215.9 & 177.8 & 10.36 \\
\hline
\end{tabular}

\subsection{Initial axial force in casing}

If cementing job quality is good, axial tension will be solidified in casing. The tension depends on casing size, density of slurry and displacement liquid, and holding pressure during cement curing. According to engineering operation, initial top axial forces $\left(F_{0}\right)$ of every casing are listed in the second column in Table 2 . These axial forces are different from actions between casing and wellhead. They can't be changed by subsequent loads on wellhead if cement job quality is good, unless temperature changes.

If surface casing has free section before production due to cementing quality, then top axial force of every casing will change. For example, surface casing appears free section immediately after cementing, then top axial force is zero and the free section has to self stand. The axial force of whole free section will change with subsequent loads acting on wellhead.

Based on above analysis, axial force of top casing is equal to its action with wellhead only when surface casing has free section.

\subsection{Parameters of casing free section}

In the following calculation, it is assumed that if surface casing has free section, intermediate casing and production casing are deemed to have free sections. According to this principle and cement job quality, empirical free section lengths $\left(L_{0}\right)$ are given as that in the third column in Table 2 .

Without loss of generality, if surface casing there exist free section, it must support the suspended loads imposed on subsequent casings when they are connected to wellhead. For intermediate casing and production casing, let setting loads be top axial tensions, as listed in the second column in Table 2.

Basing on casing size and length of free section, relationship of axial force and deformation, namely spring coefficient $(k)$, is obtained and listed in the fourth column in Table 2.

The well depth is $6600 \mathrm{~m}$, in situ temperature is about $190{ }^{\circ} \mathrm{C}$, wellhead temperature is about $90^{\circ} \mathrm{C}$ when gas flow rates is $3.0 \times 10^{5} \mathrm{~m}^{3} / \mathrm{d}$. Based on comprehensive analysis of flow rates, components, wellbore structure, flow time and free section length, free elongations $\left(\Delta L_{\mathrm{T}}\right)$ from thermal effect of each casing are listed in the fifth column in Table 2.

Table 2. Casing parameters for wellhead growth calculation.

\begin{tabular}{ccccc}
\hline Casing & $F_{0}(\mathrm{kN})$ & $L_{0}(\mathrm{~m})$ & $k(\mathrm{~m} / 10 \mathrm{kN})$ & $\Delta L_{\mathrm{T}}(\mathrm{m})$ \\
\hline $13-3 / 8 "$ & 2416.3 & 170 & 0.000661 & 0.0306 \\
$9-5 / 8 "$ & 762.57 & 170 & 0.000977 & 0.0714 \\
$7 "$ & 1313.7 & 500 & 0.007970 & 0.6480 \\
\hline
\end{tabular}

Tubing initial suspending force is $200 \mathrm{kN}$, and ground equipment is simplified as $100 \mathrm{kN}$ vertical load.

\subsection{Analysis of calculation results}

According to above parameters and methods, results are obtained in accordance with above five typical moments denoting surface casing free section appearing.

For each case, six working steps are used to analyze variations of wellhead position and casing axial force. The steps are as follows:

$\mathrm{S}(1)-13-3 / 8^{\prime}$ surface casing has cemented;

$\mathrm{S}(2)-9-5 / 8$ " intermediate casing has sit on wellhead;

$\mathrm{S}(3)-7$ " production casing has sit on wellhead;

S(4) - Tubing has hung and Christmas tree has installed;

$\mathrm{S}(5)$ - During production, wellbore temperature has risen but wellhead does not move (This step is hypothetical, for comparing with other steps.);

$\mathrm{S}(6)$ - During production, wellbore temperature has risen and wellhead growth has reached balance.

Wellhead position and casing top axial force are calculated for discussion.

\subsubsection{The change of wellhead position}

Fig. 2 shows the change of wellhead position of the four first cases, the horizontal ordinate is working steps and the vertical ordinate is wellhead position. The case-5 doesn't produce wellhead growth based on calculation, so it isn't drawn in Fig. 2. Conclusions are as follows:

- The case-1 is unique in style with a special wellhead move route. In other cases, wellhead positions have little difference from step 4.

- The changes of wellhead position from step 5 to step 6 are identical, and this is the so-called wellhead growth. This phenomenon indicates that wellhead growth is only associated with change of parameters before and after production, including temperature and pressure.

- Based on calculation, wellhead growth does not take place in case-5. This indicates that as long as surface casing doesn't have free section before production, wellhead growth cannot occur. 
- Casing suspended loads have influence on wellhead position, but they don't affect the value of wellhead growth.

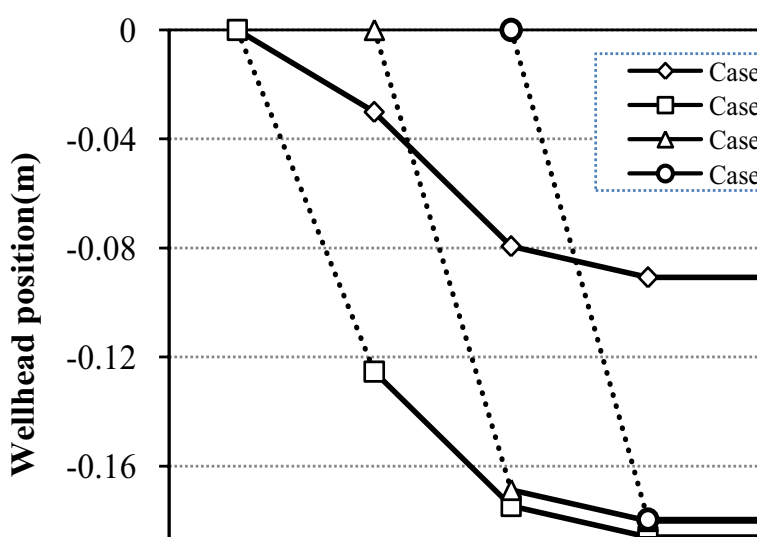

Figure 2. Wellhead position at key working steps.

\subsubsection{The change of casing axial force}

Fig. 3 to Fig. 5 show top axial forces of casing 13-3/8", 9$5 / 8$ " and 7" respectively, five cases are all considered. The vertical ordinate is top axial force of casing. Some unimportant information is neglected in these figures. It is necessary to distinguish between top axial force and acting force with wellhead, they are the same only when casing has free section, as solid part of curves in these figures.

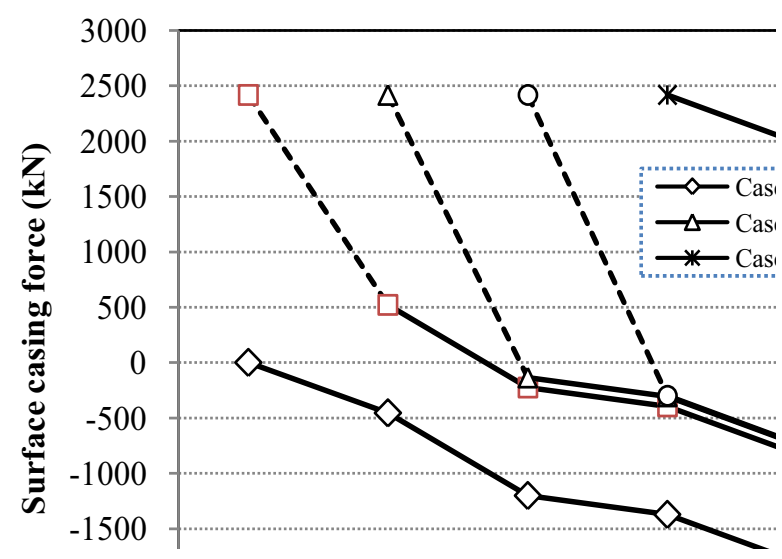

Figure 3. Axial force of 13-3/8" casing at key working steps.

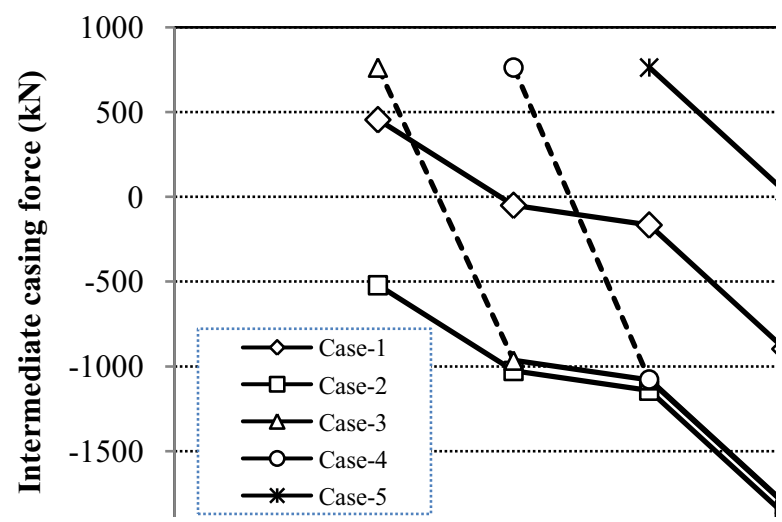

Figure 4. Axial force of 9-5/8" casing at key working steps.

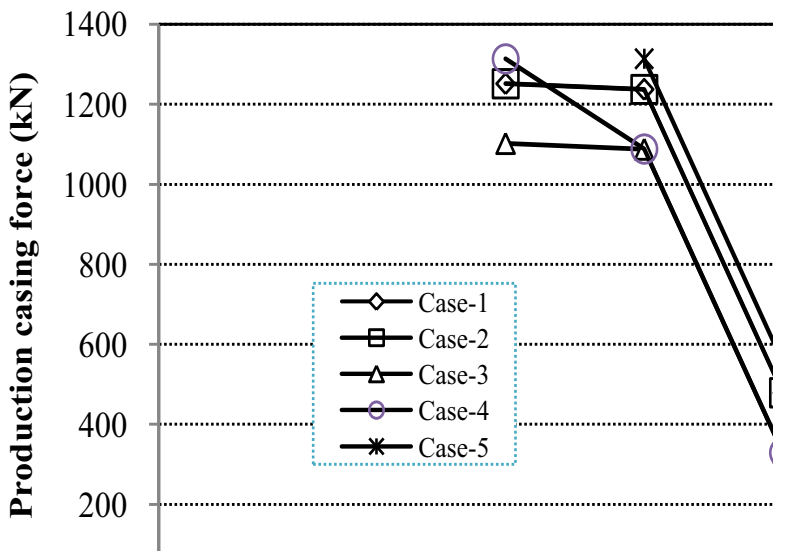

Figure 5. Axial force of 7" casing at key working steps

Combining with calculation parameters, conclusions are as follow:

- 13-3/8" casing is unique in style with a special force route in case- 1 . In case- 2 to case- 4 , axial forces have little difference.

-13-3/8" casing has the smallest axial force at step 5 and the force is press. It indicates that surface casing undertakes compressive load at wellhead, namely supports the wellhead.

- 9-5/8" casing is unique in style with a special force route in case-1. From step 2, top axial force is less than setting load due to wellhead subsidence during setting, and the decrease is transmitted to $13-3 / 8$ " casing.

- Top forces of 9-5/8" casing in case-2 to case-4 have little difference, which indicates that these three cases have little influence on wellhead growth and wellbore safety. Axial forces of four first cases are less than zero at step 5 which indicate the casing boosts wellhead upward. - 7" casing has small size and longer free section, so its top axial force change is less and is all tension. This indicates that 7" casing does not boost wellhead.

- Axial forces of 7" casing is identical in case-1 and cases-2 due to wellhead position before setting is regarded as reference position; in case- 3 and case- 4 the force are close from step 4 but not identical.

- As to case-5, calculation shows that wellhead undertakes $4800 \mathrm{kN}$ downward loads at step 4. If this force is transmitted to surface casing by accident factors, cement sheath of surface casing may be destroyed. Wellhead gets $2400 \mathrm{kN}$ upward load at step 5 which mitigates about half of downward load. Therefore, wellhead doesn't move in this case.

\subsubsection{Analysis of remedial measures}

According to analysis above, if surface casing doesn't have free section before production, there is little possibility for wellhead to grow up during production. Therefore, measures of preventing and remedying wellhead growth are as follows:

- Top-quality cement job is the best way, especially for surface casing.

- Reinforce surface casing as soon as its cementing quality is found bad. It is recommended that an enhancing 
base should be made to bear wellhead load, and the base should be placed on ground rather than on conductor.

- If wellhead growth is found during production, a bracket should be made to support wellhead, and the bracket should be placed on ground too. Meanwhile, flow rates should be controlled strictly.

\section{Conclusions and suggestions}

- Bad cement job quality of surface casing is the root of wellhead growth in deep wells; otherwise, wellhead growth doesn't take place, except in abnormal high temperature wells.

- Wellhead growth reported is a height change when wellbore temperature rises during production. So it is impossible to draw the moment of surface casing free section appearing.

- If surface casing has free section, setting loads of subsequent casings can only change axial force of free sections while wellhead growth keeps constant.

- When surface casing has free section, axial force in each casing has great change and a chain reaction may be induced to prolong the free sections.

- Countermeasures should be taken immediately if surface casing cement job quality is not ideal. Considering great loads from subsequent casings, tubing and Christmas tree, bracket for supporting wellhead should be placed on ground rather than on conductor.

\section{Acknowledgments}

This work is supported by "National Basic Research Program of China" (973 Program, 2015CB251205).

\section{References}

1. G.B. Lepper. Production Casing Performance in a Thermal Field. The Journal of Canadian Petroleum Technology, 37, 57-62 (1998)

2. Z. Jianbing, L. Jinyong, W. Yinsheng, M. Yanping, F. Xiuqin, T. Zhenchun. Study on wellhead ascension \& inclination and measures. Oil Drilling \& Production Technology, 32 Sup, 167-169 (2010)

3. A.S. Halal, R.F. Mitchell, R.R. Wagner. Multi-string Casing Design with Wellhead Movement. SPE 37443 (1997)

4. A.C. McCabe. Well Vertical Movement on Platform Wells. SPE 19241 (1989)

5. L. Xiuquan, C. Guoming, C. Yuanjiang, Z. Lei, Z. Weiguo, X. Hua. Multistring analysis of wellhead movementand uncemented casing strength in offshoreoil and gas wells. Petroleum Science, 11, 131-138 (2014)

6. K. A. Anderson. Support systems for high wellellhead loads. The Journal of Canadian Petroleum Technology, 23, 76-78 (1984)

7. S. Jing, Z. Yanru, L. Zhiyong, F. Haitao, J. Zeju. Casing Elongation Research of Conventional Wellsin the Processof Steam Injection. Oil Field Equipment, , 36, 23-25 (2007)

8. G. Baokui, G. Deli. Mechanism of Radial Separation of Cement Sheath and Casing during Temperature Cycling. Petroleum Science, 2006.

9. G. Baokui, G. Deli. Study on Well Bore Damage by Temperature Change of Underground Natural-Gas Storage Caverns. Science Press USA Inc., 360-365 (2005)

10. G. Baokui, G. Deli. Shearing Damage of CasingCement Sheath Interface from Temperature Changing in Well Bore. Science Press USA Inc., 2443-2447 (2006) 